\title{
SILK INVESTMENT IN GIFTS BY MALES OF THE NUPTIAL FEEDING SPIDER PISAURA MIRABILIS (ARANEAE: PISAURIDAE)
}

\author{
by
}

\begin{abstract}
ANDREAS LANG ${ }^{1,2)}$
(Zoologisches Institut, Ludwig-Maximilians-Universität, Karlstraße 23, 80333 München, Germany)
\end{abstract}

(Acc. 31-I-1996)

\begin{abstract}
Summary
Adult males of the hunting spider Pisaura mirabilis wrap up prey with silk and pass these nuptial gifts to females prior to copulation. The females digest the nuptial gifts, including the silk, during mating. Laboratory experiments were carried out to determine the amount of silk males of $P$. mirabilis invest in nuptial gifts, and its possible role in sexual reproduction. The amount of silk was always small, indicating that the silk of the nuptial gift has little nutritional value for females. Males that had more time to wrap up the prey produced a larger amount of silk. Starved males required more time than satiated males to produce a given amount of silk. A larger male body size had a positive effect on the amount of silk. In general, the size of the prey used for nuptial gifts had no influence on the amount of silk. However, due to handling problem, smaller males produced no silk for very large flies. Females took more time to digest a nuptial gift with a larger amount of silk than a nuptial gift with a smaller amount of silk. A possible interpretation of the adaptive significance of wrapping is that males use silk to prolong the copulation time during mating.
\end{abstract}

1) Present address: GSF-Forschungszentrum für Umwelt und Gesundheit, Institut für Bodenökologie, Neuherberg, Postfach 1129, 85758 Oberschleißheim, Germany; e-mail: lang@gsf.de

2) I would like to thank Albert Klarenberg for enabling and supporting this work. I thank Jürgen Jacobs, Raymond Leborgne, Alain Pasquet, Juliane Filser and two anonymous referees for their critical comments that considerably improved the manuscript. I am grateful to Steven Austad for informations on unpublished results, Jürgen Jacobs for valuable discussions, and Juliane Filser for her support. I thank Steve McLaughlin for correcting my English. 


\section{Introduction}

In many species of insect, males pass 'nuptial gifts' to females during courtship and copulation. These gifts may consist of food (e.g. a prey item), spermatophores or other material synthesized by the male (e.g. Thornhill \& Alcock, 1983; Zeh \& Smith, 1985). In some species, the size of the nuptial donation is positively correlated with copulation time during mating and number of sperm transferred, and therefore probably also with male reproductive success (e.g. Thornhill, 1976; Sakaluk, 1985, 1986; Svensson et al., 1990). The nuptial givings sometimes bring nutritional benefits to the mated females and a reproductive utilization of such male donations by the females has been shown (Butlin et al., 1987; Simmons, 1988). For this reason courtship feeding has often been regarded as a form of 'paternal investment' (Simmons \& Parker, 1989), an interpretation that requires the assumption that the donating male is expected to father all or the majority of the offspring (Wedell, 1993). Alternatively, the nuptial gift may constitute a form of mating effort, leading to an increase in male fertilization success (Wickler, 1985, 1994). This assumes that providing females with a donation during copulation faciliates the transfer of sperm to the female. There are examples of both possible functions, which are not mutually exclusive. In Orthoptera, for example, large gifts have been shown to represent paternal investment; by providing the females with the donation, the male is able to increase the number and survival of its offspring (Gwynne, 1986, 1988). However, small offerings only increase male fertilization success, and not egg number or the chances of survival of the offspring (Wedell \& Arak, 1989). It has therefore been classified as mating effort. The time that the females require to consume the gift is positively correlated with the mass of the gift, and males may adjust the size of the gift to gain the time necessary for a successful insemination (Sakaluk, 1985; Wedell \& Arak, 1989; Heller \& Reinhold, 1994).

Studies of nuptial feeding in arthropods other than insects are rare. As far as we know, the males of only one spider species, P. mirabilis (Clerck), a hunting spider, pass prey they have caught themselves to females prior to copulation. The males wrap up prey with silk, and the females digest these prey items together with the silk during mating (Nitzsche, 1988). Female $P$. mirabilis allow males with larger nuptial gifts to mate longer, and a higher feeding rate enhances the fecundity of the female (Austad 
\& Thornhill, 1986). Both facts indicate that nuptial gifts may play an important role for females with respect to reproduction. Since the nuptial gift of $P$. mirabilis contains two potentially nutritional components, prey and silk, the question arises of how much the silk may contribute to the total benefit of the gift. Since males can manipulate the amount of silk used for wrapping up a prey, this component of the nuptial gift may play an important role in sexual selection.

Although the wrapping up of the nuptial gift by males of $P$. mirabilis is well known, and was investigated intensively by Nitzsche (1987), until now there has been no study of the amount of silk the males invest in nuptial gifts nor of its function with regard to sexual behaviour. This study quantifies the amount of silk in nuptial gifts in P. mirabilis. Furthermore, factors influencing this amount were investigated. Knowledge of these facts is essential for an understanding of the function of the silk in the mating context of this species. The following points were therefore of particular interest:

1. The amount of silk in nuptial gifts of different sizes.

2. The influence of previous silk production, and of body size and hunger state of the males on the amount of silk.

3. The influence of the time available for males to wrap up the gift on the amount of silk.

4. The time required by the females to digest gifts with different amounts of silk.

\section{Nuptial gifts and mating behaviour of $P$. mirabilis}

As mentioned above, P. mirabilis are the only known spiders which present prey they have caught themselves as nuptial gifts. One related species in the family Pisauridae, Thaumasia uncata, is suspected of offering nuptial gifts (Nitzsche, 1988), but this has not been yet proven. The mating habits of other Pisaura species are not known. Although the nuptial feeding behaviour of $P$. mirabilis has been known for a long time and has frequently been described (e.g. Gerhardt, 1923; Bristowe \& Locket, 1926), only a small amount of exact data exists on the mating behaviour of this species. In the first days after their moult to adulthood, males appear to catch prey mainly for their own nutrition. A few days later they start to wrap and carry around prey (Nitzsche, 1987; pers. obs.). They probably feed on the prey 
item while carrying it (Nitzsche, 1987, 1988). The prey taxa mainly found in nuptial gifts of $P$. mirabilis are Diptera, Araneida and Hemiptera, and the gifts may contain more than one prey item (Pénicaud, 1979; Nitzsche, 1988). The size of the prey can be in the range of small fruit-flies to large blow-flies $\left(0.4\right.$ to $\left.42 \mathrm{~mm}^{3}\right)$, but most prey is smaller than $20 \mathrm{~mm}^{3}$ (Nitzsche, 1987). In the field, an average of $35 \%$ of adult males carry a prey item, and $80 \%$ of the gifts are wrapped up with silk (Nitzsche, 1988). The prey is usually wrapped up with silk in three steps: first, immediately after the male has caught the prey, then, in the period where the male is carrying the prey in search of a female, and finally, when the male meets the female.

Upon meeting a female, a male usually starts stroking her with the first pair of legs. The female remains motionless, the legs pressed closely to the body. Next, the male moves to the front, vis à vis the female, and presents his nuptial gift. The female approaches slowly, grasps the gift, and copulation commences. The female starts to feed on the nuptial gift during copulation, but discontinues copulation after a certain time, and finishes digesting the prey item on her own. The duration of a successful copulation, i.e. leading to insemination of the eggs, can vary between $31 \mathrm{~s}$ and $141 \mathrm{~min}$ (Nitzsche, 1987). If the male does not have a nuptial giving, the female breaks off the mating at once. The third step of wrapping up the gift can occur at any phase before the female actually receives it, but it is usually finished before the male presents his gift. Each of the behaviour elements described above, including wrapping up of the nuptial gift, is sometimes omitted prior to copulation (after Nitzsche, 1987; pers. obs.).

Both males and females can copulate several times in a lifetime: Nitzsche (1987) observed up to six copulations in the laboratory, and Austad \& Thornhill (1986) saw P. mirabilis in the field "copulating with more than a single mate during the course of the season".

After contact with a female or with female silk threads, the males of P. mirabilis also show certain behavioural elements which I will refer to as 'sexual excitement': trembling of the palps and abdomen, jerking of the body, moving in jerks, and rapid rubbing of the legs. The males do not necessarily show all these behaviour elements (after Gerhardt, 1923; Bristowe \& Locket, 1926; Le Pape, 1974; Nitzsche, 1987; pers. obs.). 


\section{Methods}

\section{Animal collection and rearing conditions}

Juvenile $P$. mirabilis were collected from two populations near Munich, Germany. In early spring and autumn, 209 animals (133 males and 76 females) were captured. The spiders were kept singly in plastic boxes $(8 \times 11 \times 4 \mathrm{~cm})$ and raised to adulthood in the laboratory. Juveniles were fed ad libitum with flies of various species of Drosophila, Musca and Lucilia. Adults were fed one Calliphora every seven days. The spiders had a constant supply of water from a moistened cotton pad. The laboratory temperature was about $22^{\circ} \mathrm{C}$, relative humidity $70 \%$ and the day-night-cycle $16: 8 \mathrm{~h}$. All experiments were conducted in plastic boxes $(19 \times 12 \times 12 \mathrm{~cm})$ lined with clean paper.

\section{Silk production experiments}

At the beginning of an experiment, an adult virgin female was placed in the experimental box. She was removed after $5 \mathrm{~min}$ and a male was introduced. The silk threads left by the female served to initiate 'sexual excitement' (see Introduction) in the males, which made them more willing to accept a fly provided by the experimentator. As soon as the male showed 'sexual excitement', he received a fly. Immediately afterwards (SPE I and II, see below) or after a variable time between 1 and $24 \mathrm{~h}$ (SPE III), a female was introduced into the box. Once the male had touched the female in the way described (see Introduction), the female was removed. After the removal of the female, the male was given 10 min to wrap up the fly (observations had shown that wrapping up of the nuptial gift after having encountered a female occured mainly in the first $10 \mathrm{~min}$ ). When $10 \mathrm{~min}$ had expired, the fly was removed with pincers to determine the amount of silk produced by the male. During the 10 min of the experiment, the actual spinning time of the male was recorded.

Sometimes the male immediately offered the fly to the female without wrapping, or started to wrap it up without having touched the female. In these rare cases, the female was removed at that point. All experiments where the female attacked the male or vice versa were terminated immediately. Experiments were also stopped if the spiders were disturbed by experimental handling.

In all experiments, adult age (defined as days since the moult to adulthood), length of the 4th tibia and width of cephalothorax of male and female spiders were measured. This was done to check the possibility that these factors may influence the amount of silk in the nuptial gift.

\section{Measurement of silk production}

Nuptial gifts obtained in the course of the experiments (flies plus silk) were first frozen at $-7^{\circ} \mathrm{C}$ and the silk then separated from the fly under a stereo microscope. This approach reduced the risk of polluting the silk with insect body fluid through accidental injury to the fly. Soiled silk samples, which can be recognised due to colouring of the white silk, were omitted from further analysis. The silk was dried at $100^{\circ} \mathrm{C}$ for $15 \mathrm{~h}$ and then placed in a dessicator. After about $24 \mathrm{~h}$, the silk was weighed with a balance to the nearest $0.01 \mathrm{mg}$. 
SPE I

Three sets of silk production experiments were carried out (SPE I-III). SPE I was carried out to determine the amount of silk in nuptial gifts of different sizes. Various dipteran species were collected in the field (ranging in size from Drosophila to Calliphora), and their size (length $\times$ width) and weight measured. Before a fly was given to a male, it was killed, and wings and legs removed to simplify subsequent separation of the silk. The males received their last meal 3 days before the experiment.

\section{SPE II}

The first objective of SPE II was to study whether the wrapping up of a prey on one day decreases the amount of silk production on the subsequent day. In order to check whether the size of the fly was a possible influencing factor, this experiment was carried out with two fly types: Musca sp. as a small prey, and Calliphora sp. as a large one. The flies were killed shortly before the experiment, and the wings, legs and head were removed. The males received their last meal 3 days before the experiment. One group had to wrap up a small fly on the first day and a large fly on the second day (approx. 22-26 h later), whereas the other group was given the opposite task. The production of silk on the first and the second days was compared for each type of fly.

The second objective of SPE II was to analyze whether a different hunger state of the males has an influence on the amount of silk produced. To check whether the size of fly was an influencing factor, the males again received a small and a large fly (one approx. 22-26 $\mathrm{h}$ after the other). One group of males received its last meal 3 days and the other group 12 days before the experiment. In the following discussions, these two groups are referred to as satiated males and starved males. The silk production was then compared between satiated and starved males, for each size of fly separately.

\section{SPE III}

SPE III was carried out to determine whether males produce more silk when they are given more time than in the experiments described above prior to contact with a female. Three days after the last meal, a male was put into a box with female silk threads. When he showed 'sexual excitement', he was given a fly of standard size (Musca sp., killed, and wings, legs and head removed, size $12.7 \pm 0.46 \mathrm{~mm}^{2}$, fresh weight $16.1 \pm 0.75 \mathrm{mg}$, dry weight $5.3 \pm 0.25 \mathrm{mg}, N=23$, mean $\pm \mathrm{SE}$ ). He was then permitted to carry around the prey for different periods of time, and to wrap it up in the absence of a female. At some variable point of time during the next $24 \mathrm{~h}$, the male was put into the experimental box containing a female. After he had touched the female, the latter was removed, and the male was permitted to wrap up the prey for an additional $10 \mathrm{~min}$. The amount of silk in the nuptial gift was determined at the end of this $10 \mathrm{~min}$, i.e. the total amount of silk consisted of silk produced during the earlier carrying time without the presence of a female plus the silk produced within the subsequent 10 min after contact with a female. The actual spinning time of the male was recorded only for the 10 -min period. 


\section{Feeding time of females}

This experiment was carried out to study the effect of different amounts of silk in the nuptial gift on the feeding time required by females to consume the wrapped prey. Heads of Lucilia sp. which had been wrapped up by 'sexually excited' males were used as prey for nuptial givings. The wrapped gifts were weighed and then offered to the females. The time the females needed to consume these nuptial donations was measured. The females had had their last meal 3 days before the experiment. Two groups of females were formed: one group received a wrapped prey with a small amount of silk, another group a wrapped prey with a larger amount of silk. Here the spinning time of the males when wrapping up these nuptial gifts served as a relative measurement of the amount of silk (for the significant positive correlation between spinning time and amount of silk, see Table 2). This indirect measurement was chosen for the following reason: when spiders catch a fly they pierce it's cuticula which leads to a certain weight loss in the prey item through evaporation. That is why weighing twice (before and after prey wrapping) gives not more precision.

\section{Results}

Silk production experiment I (SPE I)

In this experiment, the amount of silk in nuptial gifts of different sizes was determined. This was tested to assess two possible reasons why this amount may vary with size of prey: first, if males produce a fixed proportion of silk with respect to the size of the prey, then absolute amount of silk should correlate positively with size of fly; second, if males use silk to increase the size of small flies, absolute amount of silk should correlate negatively with size of fly.

The size of the flies ranged from $6.6-34.7 \mathrm{~mm}^{2}\left(20.0 \pm 9.0 \mathrm{~mm}^{2}\right)$, the fresh weight from $4.1-58.3 \mathrm{mg}(21.3 \pm 15.6 \mathrm{mg})$, and the dry weight from $1.1-21.3 \mathrm{mg}(6.7 \pm 5.0 \mathrm{mg})$ (means $\pm \mathrm{SD}$ in parentheses). For wrapping up these flies of various sizes, males produced a broad range of silk (0.02$0.12 \mathrm{mg}$, Fig. 1). The mean amount ( $\pm \mathrm{SD}$ ) was $0.050 \pm 0.03 \mathrm{mg}$. The proportion of the silk in the total nuptial gift (silk dry weight $\times 100 /$ (silk dry weight + fly dry weight)) was very low: it ranged from $0.18-3.47 \%$ (mean $\pm \mathrm{SD}: 1.06 \pm 0.80 \%$ ).

There was no correlation between the size of the fly and the absolute amount of silk in the nuptial gift (Spearman correlation coefficient, $r=$ $0.12, p>0.05$ ). The proportion of the silk in the nuptial gift showed a significant negative correlation with size of fly $(r=-0.62, p<0.01)$, i.e. 


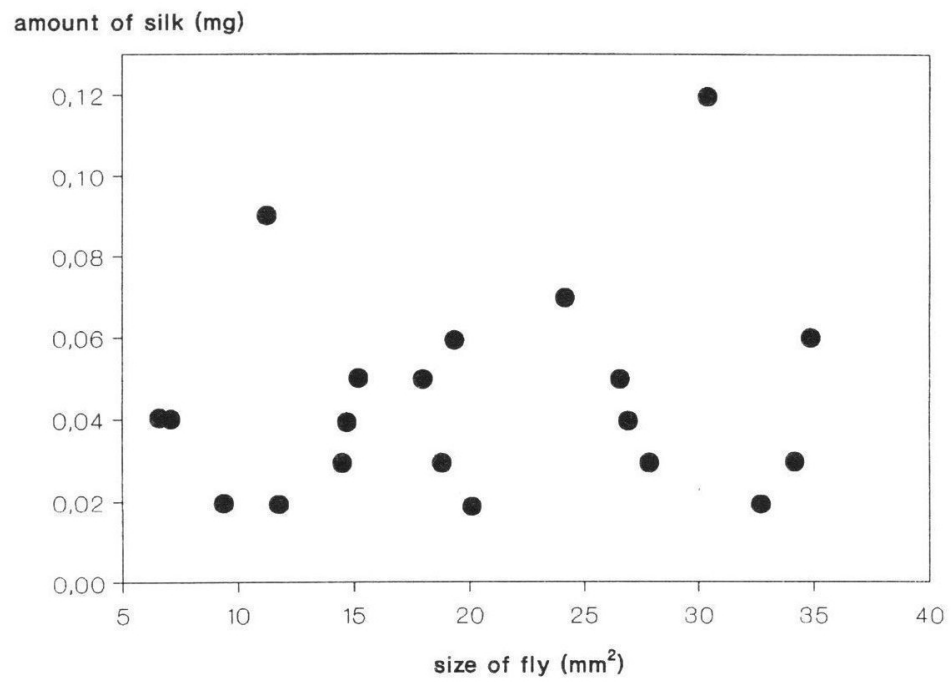

Fig. 1. Relationship between the amount of silk in the nuptial gift and the size of flies (SPE I). $N=20$.

the relative amount of silk was lower in larger gifts. This suggested that each male produced a certain amount of silk for his nuptial gift, irrespective of the size of the fly.

In conclusion, the main results of this experiment were that the silk was only a minor part of the nuptial gift (in terms of weight), that the variance of the amount of silk production was large, and that the males did not adjust their production of silk to prey size.

\section{Silk production experiment II (SPE II)}

This set of experiments is related to the costs involved for males in producing silk. A previous investment of silk, and a poor nutritional state of the males may both be circumstances in which such a cost is incurred. If silk production is costly for males, both facts should lead to a diminished amount of silk. If males are able to judge the value of their gift, these costs might only be apparent in large gifts, i.e. if large prey induce a long enough copulation time, why should males add silk if it is too costly for them. Therefore, the experiments in SPE II were carried out with flies of two different sizes. 
The first objective of SPE II was to study whether a previous silk production had an effect on the amount of a subsequent silk production. The experiments generally showed that a silk production the day before had no significant influence on the silk amount produced the following day, irrespective of the size of the fly (Mann-Whitney $U$-test, $p>0.05$, Fig. 2A).

The second objective of SPE II was to study whether a different nutritional state of the males has an influence on the amount of silk produced. In both fly sizes there seemed to be a tendency towards a smaller silk amount in starved males, but this difference was not significant (MannWhitney $U$-test, $p>0.05$, Fig. 2B). It should be noted that satiated males and starved males did not differ significantly in adult age, length of the 4th tibia or cephalothorax width. There were also no differences in size and fresh weight of small and large flies (Mann-Whitney $U$-test, $p>0.05$, Table 1). Thus any possible effect of these variables on the amount of silk was randomized within the treatments.

In conclusion, neither a silk investment the day before nor hunger decreased the amount of silk significantly, irrespective of fly size. This indicated that silk production was not very costly to males.

However, there were significant differences between satiated and starved males with regard to the spinning time, the silk production efficiency, and the effect of male body size. The mean spinning time to wrap up a fly was shorter in satiated males than in starved males, and satiated males generally required less time to produce $0.01 \mathrm{mg}$ silk (Mann-Whitney $U$-test, $p<0.05$ in both cases, Table 2). Satiated males showed a stronger positive correlation between spinning time and amount of silk, and the positive effect of male body size on the amount of silk was only found for satiated males (Table 2).

These results mean that hunger reduces the efficiency of silk production. In end effect, this had no influence on amount of silk, because starved males compensated for their less efficient silk production by spending more time in wrapping up the prey.

\section{Cases of non-wrapping-up}

Sometimes males did not wrap up the flies. These cases of non-wrappingup were not included in the above analysis of SPE II, but will be discussed separately in this section. Whereas both satiated and starved males wrapped 


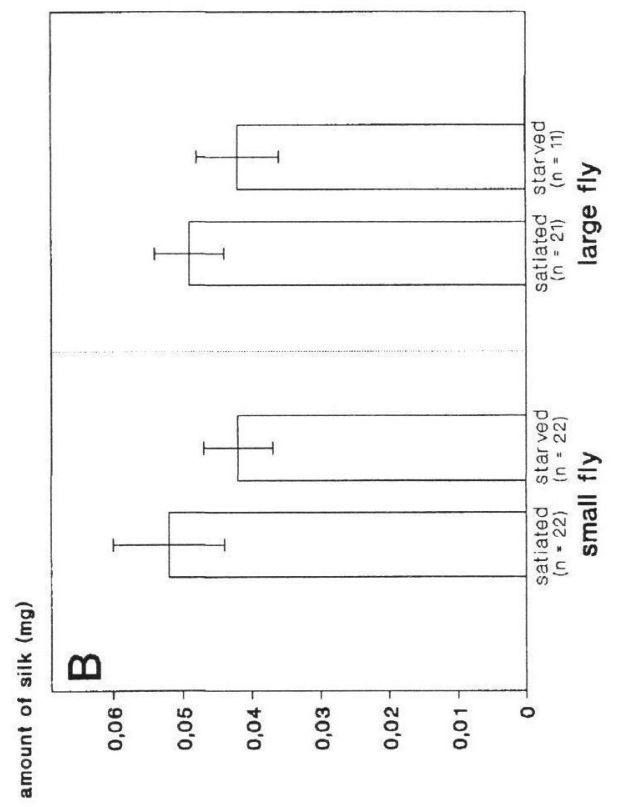

ह

్ㅠ

๑

Е

क्ञّ है

리을

호 휴

$\Xi$ क

를 믐

虫命

节总芯

品

¿ 늠

ธี Ј

卺

䓀

岁总 可

过 त

के ठี

켤 坖

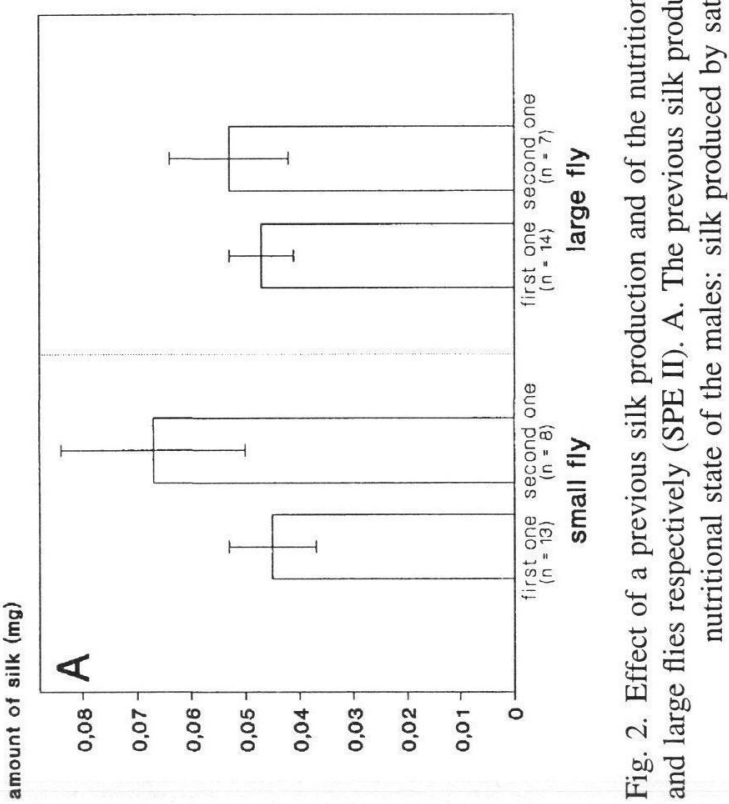




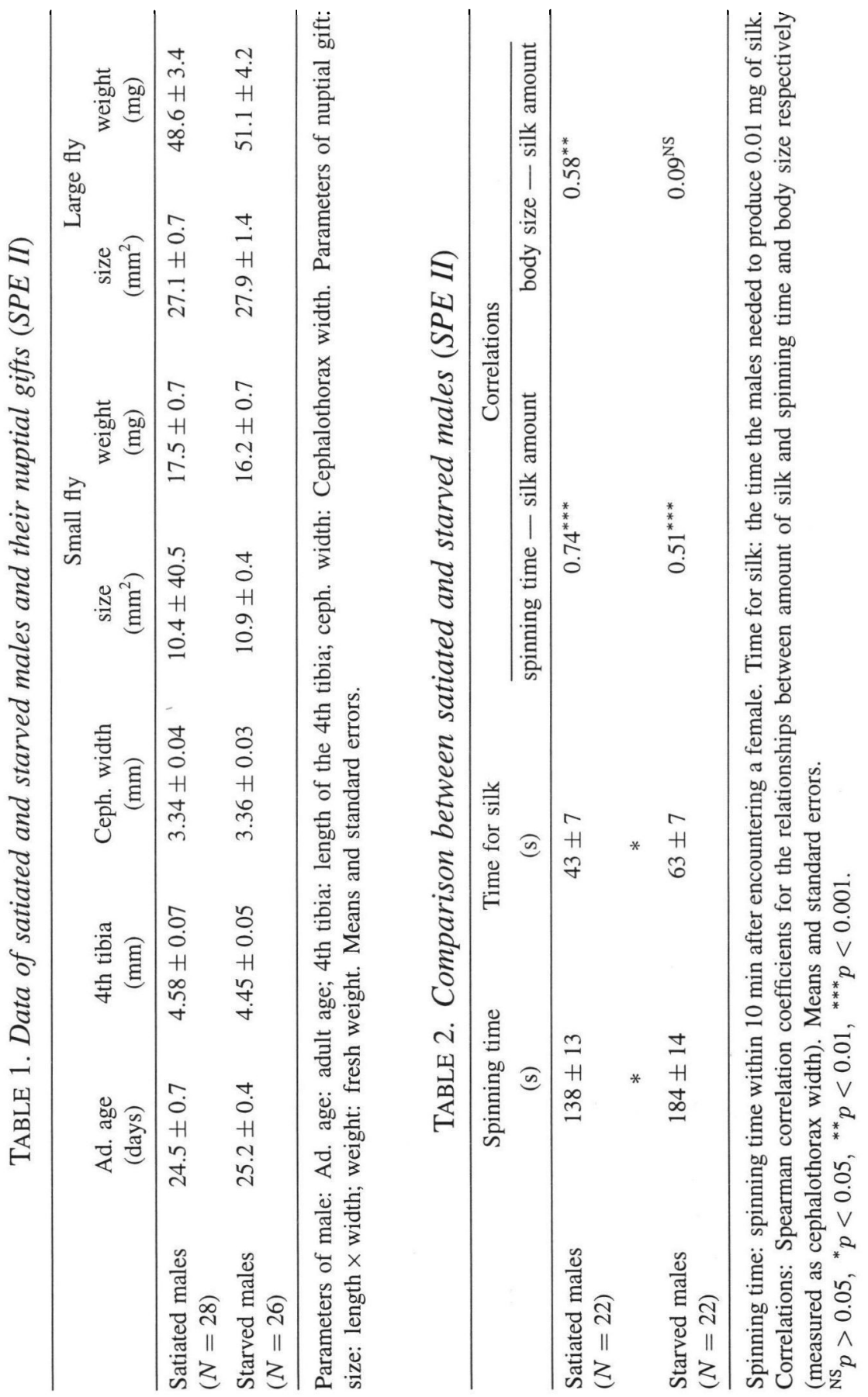


up all the small flies, some did not produce silk for the large flies. The percentage of 0-productions was significantly higher in starved males (62\%) than in satiated males $(28 \%)\left(\chi^{2}=4.65, p<0.05\right)$. Hunger thus seemed to reduce the capacity to wrap up a large fly. The body size of males had had an influence on the fact whether a large fly was wrapped up or not. The males (satiated and starved pooled together) which wrapped up the flies $(N=28)$ had a larger cephalothorax width and a longer 4th tibia than the males which did not $(N=17)$ (Mann-Whitney $U$-test, $p<0.05)$. All the males which did not wrap the large fly were observed wrapping up smaller flies. This ruled out inability to produce silk as a possible explanation. All these males were 'sexually excited' in the experiments, and 59\% of these males offered the large fly to the encountered female immediately. This suggests that these males were willing to mate, and to use the large fly as a nuptial gift.

Direct observations revealed that small males had difficulties in wrapping up large flies. Usually the males circle around and above the prey, fixing it to the substrate as well as covering it with silk. Due to the size of a large fly, males generally had more difficulties in moving their opisthosoma over it. As a consequence, smaller males had more problems in fixing large flies to the substrate. Covering the fly with silk without fixing it beforehand appeared to present difficulties. The unfixed fly was moved and also turned when the males circled around it, thus preventing a wrapping with silk.

The conclusion is therefore that the 0-productions are caused by handling problems rather than by a 'decision' by the males to produce less silk for this particular prey. Nevertheless, hunger seemed to enhance these problems, possibly by weakening the males' general constitution.

\section{Silk production experiment III (SPE III)}

In this experiment, the males were allowed to carry around their nuptial gifts (Musca sp.) for different lengths of time (1-24 h). The purpose of this was to analyse whether there was a positive relationship between carrying duration and the amount of silk. Figure 3 shows that there was no correlation between the amount of silk and the investigated carrying time of the nuptial gift (Spearman correlation coefficient, $r=0.26, p>0.05$ ).

To test whether the longer carrying time resulted in a higher amount of silk, and to determine this increase, the results of SPE III were compared 


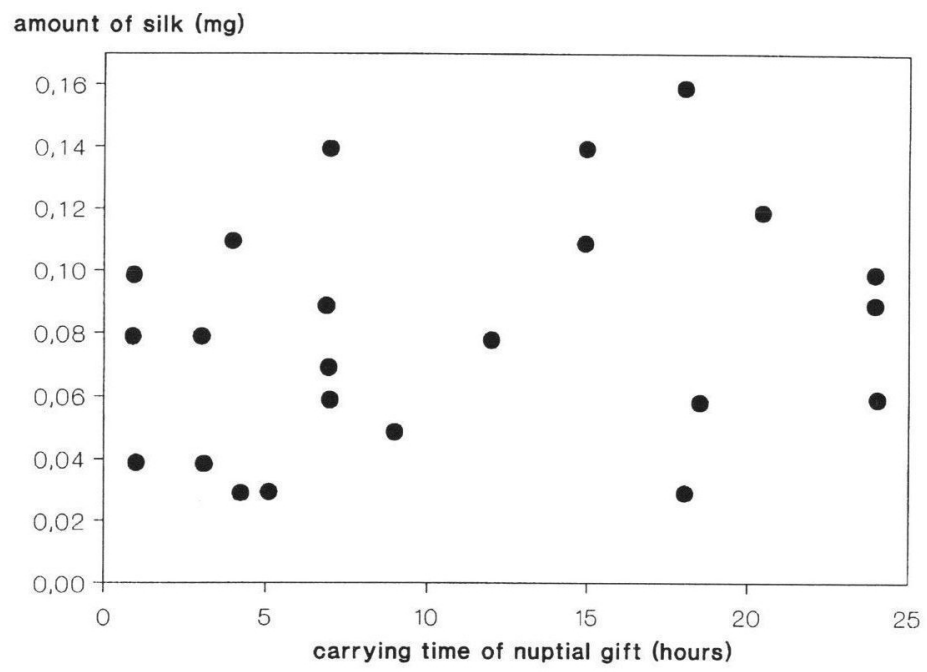

Fig. 3. Relationship between the amount of silk in the nuptial gift and the carrying time of the nuptial gift (SPE III). The prey used for nuptial gift was a Musca fly of standard size.

$$
N=23 \text {. }
$$

to the data from SPE II (Table 3). In the cases where males were used for both experiments, only the values for SPE III were taken into account. Males which carried their nuptial gift for 1-24 h (SPE III) produced on average twice as much silk as the males in SPE II which only had 10 min to wrap up their prey (Mann-Whitney $U$-test, $p<0.001$ ). Moreover, the proportion of silk relative to male dry weight, and the proportion of the silk in the nuptial gift was about twice as high in SPE III as in SPE II (Mann-Whitney $U$-test, $p<0.001$ in both cases). Although the SPE III males produced more silk, their spinning time within the $10 \mathrm{~min}$ after encountering a female was shorter (Mann-Whitney $U$-test, $p<0.001$ ).

This means that the increased amount of silk was produced during the longer carrying time. However, as mentioned above, no positive correlation was found between the investigated carrying time and the amount of silk in the nuptial gift. This indicated that the males produced most of the silk within a short space of time. Direct observations suggest that this probably happens shortly after having caught the prey. 


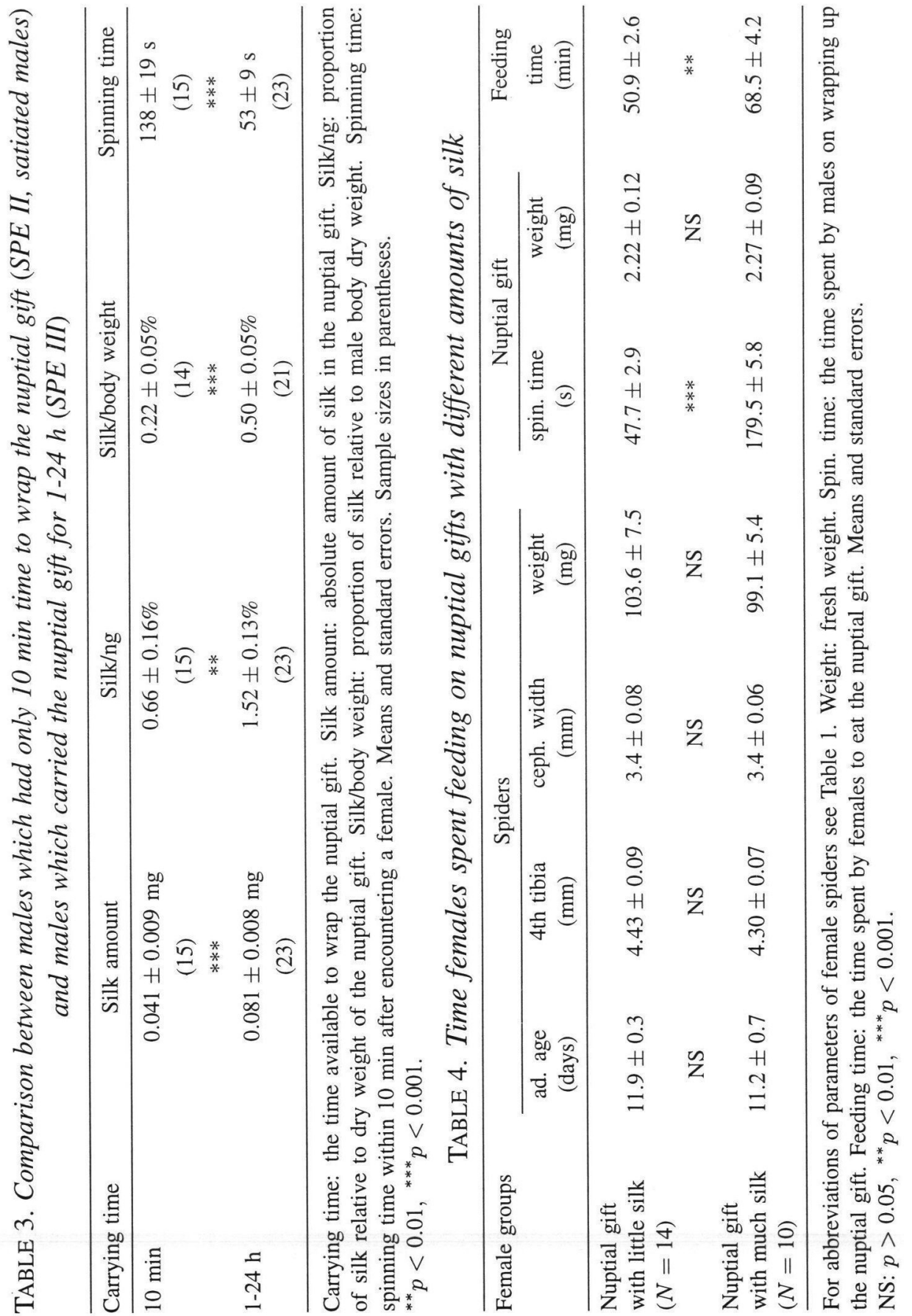


Feeding time of females

This experiment was carried out to study the effect of different amounts of silk in the nuptial gift on the feeding time required by females to consume this wrapped prey. Females of $P$. mirabilis required $68.50 \pm 4.18 \mathrm{~min}$ $(N=10)$ to digest small nuptial gifts with a large amount of silk (= long spinning time) as opposed to $50.86 \pm 2.60 \mathrm{~min}(N=14)$ for nuptial gifts of the same prey size but with a small amount of silk (= short spinning time) (Mann-Whitney $U$-test, $p<0.01$, Table 4). The two female groups did not differ significantly in adult age, length of the 4th tibia, weight of the females, and fresh weight of nuptial gifts (Mann-Whitney $U$-test, $p>0.05$, Table 4). In other words, there was on average a $25 \%$ difference in female feeding time due to the difference in the amounts of silk on the nuptial gift. It should be emphasized that the proportion of silk in the gift was very small in both cases (probably less than 3\%, cf. SPE I, Fig. 1).

\section{Discussion}

The amount of silk in the nuptial gift

My data has shown that male $P$. mirabilis produce only a small amount of silk in nuptial gifts. The proportion of silk produced per male body dry mass is also very small. By way of comparison, females produce about five times more silk for cocoons than males produce for their nuptial givings (Lang, unpubl. data). Other arthropods (e.g. Orthoptera) can invest a good deal more 'male body-derived substances' in nuptial givings, for instance up to $20 \%$ or $25 \%$ of male body fresh weight (Gwynne, 1986; Heller \& Reinhold, 1994). This shows that males of P. mirabilis normally invest little in terms of weight of their own body substance in mating.

\section{Factors influencing the amount of silk}

When males had more time to wrap up the nuptial gift before encountering a female, they produced more silk. Although the presence of a female stimulates wrapping up behaviour in males, this presence is not necessary (Leighton, 1969; Le Pape, 1974). Nitzsche (1987) showed that isolated males may wrap up their prey repeatedly over a certain time period. This, 
and the results of my study, demonstrate that males wrap up their nuptial gift in advance to cater for the possibility they might meet a female. Field data also supports this view: $80 \%$ of nuptial gifts in the field are wrapped up without females being present (Nitzsche, 1987). The advantage of this behaviour may be that males then have to devote less time to wrapping after having encountered a female. This can be important, as females sometimes retreat while the male is wrapping up the prey (Lang, pers. obs.). Unfortunately, the work of Nitzsche (1987) offers no explanation for the other $20 \%$ of non-wrapped prey. There are several possible reasons why males carried an unwrapped prey. Possibly the prey item had just been caught and males had not yet started to put silk on it. Or maybe the males did not want to use the prey as a gift and consumed it themselves, as they sometimes do in the first few days after their moult to adulthood (Nitzsche, 1987). Or maybe the males had difficulties handling the prey (see below).

Larger males produced more silk. It is possible that larger males have larger spinning glands. A positive correlation between spider body size, spinning glands and silk production was found in the Lycosidae (Araneae), a family closely related to the Pisauridae (Richter, 1970). This would correspond to some nuptial feeding species of Orthoptera (Insecta), where a positive relationship exists between male body weight, weight of the nuptial donation and size of glands producing this donation (Heller \& Reinhold, 1994). In P. mirabilis, body size provides an extra feature: larger males can handle prey better, and are thus able to wrap up even very large prey items.

Starvation reduced the efficiency of male silk production. It negated the positive effect of male body size on amount of silk, and it decreased the percentage of wrapped large flies. These results were not caused by a short supply of the silk stored in the spinning glands. This is shown by the fact that starved males could compensate for their less efficient silk production by spending more time in wrapping up the prey, thus producing a similar amount of silk as satiated males. It is more likely that starvation weakened the general constitution of the males, which in turn increased handling problems, especially with large and heavy prey items. 


\section{The possible function of the silk}

In insects, the amount of nutritional benefits invested by males in females during mating may be important for the reproductive output of the females (e.g. Gwynne, 1986; Butlin et al., 1987; Simmons, 1988). In spiders, silk may be such an investment. It consists mainly of proteins, and female P. mirabilis appear to digest the silk of the nuptial gift (Nitzsche, 1988). In nuptial feeding Orthoptera in general, only large donations, which have been shown to be costly for males, benefit the females' reproductive output, whereas small donations seem more likely to represent a mating effort of the males to ensure sperm transfer (Gwynne, 1986; Wedell \& Arak, 1989; Reinhold \& Heller, 1993; Heller \& Reinhold, 1994). My study suggests that silk is probably not very costly for males. This and the result that the amount of the silk relative to the prey in the nuptial gift is very small indicates that silk has a low nutritional value for the females, and thus has little importance for the reproduction of the female. Even when taking into account that the males consume a small portion of the gift while carrying it around (Nitzsche, 1988), the contribution of the silk to the nuptial donation still remains very small in terms of weight; at least after the $24-\mathrm{h}$ period of observation. The data of my study cannot rule out the possibility that the male silk contains special substances essential to the females, even in small amounts. This seems to be the case in some insects, where the presence of certain substances even in small amounts lead to a substantial increase in egg production (Gwynne, 1988). But this is very unlikely in the case of $P$. mirabilis, as one would then expect silk to be an important nutrition for males too. But when males fail to encounter a female, they discard the nuptial gift together with the silk after a few days (Lang, unpubl. data) even so their digestive enzymes are capable of dissolving the silk (Nitzsche, 1988).

In nuptial feeding insects, the quantity of the nutritional donation can be positively correlated with the subsequent feeding time of the females (Sakaluk, 1985; Wedell \& Arak, 1989; Reinhold \& Heller, 1993), and with the duration of the copulation (e.g. Svensson et al., 1990). In insects as well as in spiders, a longer copulation duration can be positively related to the amount of sperm transferred, and therefore probably also to the fertilization success of males (Thornhill, 1976; Austad, 1984; Sakaluk 1985, 1986). In P. mirabilis, males with larger nuptial gifts mate longer and fertilize more 
eggs of the female they mate with (Austad \& Thornhill, 1986; Austad, pers. comm.). In this study, female $P$. mirabilis fed longer on small nuptial gifts with a higher silk amount. A possible effect of silk might therefore be to prolong the feeding time of females when digesting the nuptial gift. This could increase copulation duration, which in turn would enable males to transfer more sperm and thus lead to greater fertilization success. However, the suggested use of silk by males to manipulate females needs further clarification. First, mating experiments with nuptial gifts of equal prey size but different amounts of silk should be conducted to quantify the influence of silk amount on copulation time. Second, experiments with nuptial gifts of different prey sizes should be carried out to investigate whether the effect of silk on feeding time is the same for all sizes of prey.

This suggested function of the silk in the nuptial gift does not necessarily exclude other functions. Prey wrapped up with silk may be easier to carry for the males and males sometimes combine several prey items by spinning them together (Nitzsche 1987, 1988). Nevertheless, my data shows that the silk in the nuptial gift has a definite function in the mating process. First, males which were provided with a fresh and unwrapped prey, wrapped it immediately on sensing and encountering a female. Second, males with unwrapped prey wrapped longer after having encountered a female than males which had already wrapped their prey. Finally, the majority of males which had already wrapped their prey wrapped it up again immediately after having met a female.

\section{References}

Austad, S.N. (1984). Evolution of sperm priority patterns in spiders. - In: Sperm competition and the evolution of animal mating systems (R.L. Smith, ed.). Academic Press, New York, p. 223-249.

— - \& Thornhill, R. (1986). Female reproductive variation in a nuptial-feeding spider, Pisaura mirabilis. - Bull. Br. arachnol. Soc. 7, p. 48-52.

Bristowe, W.S. \& Locket, G.H. (1926). The courtship of British Lycosid spiders, and its probable significance. - Proc. Zool. Soc. London 22, p. 317-347.

Butlin, R.K., Woodhatch, C.W. \& Hewitt, G.M. (1987). Male spermatophore investment increases female fecundity in a grasshopper. - Evolution 41, p. 221-224.

Gerhardt, U. (1923). Weitere sexualbiologische Untersuchungen an Spinnen. - Arch. Naturgesch. (Abt. A) 89, p. 1-225. 
Gwynne, D.T. (1986). Courtship feeding in katydids (Orthoptera: Tettigoniidae): investment in offspring or in obtaining fertilizations? - Amer. Nat. 128, p. 342-352.

- - (1988). Courtship feeding in katydids benefits the mating male's offspring. - Behav. Ecol. Sociobiol. 23, p. 373-377.

Heller, K.-G. \& Reinhold, K. (1994). Mating effort function of the spermatophore in the bushcricket Poecilimon veluchianus (Orthoptera, Phaneropteridae): support from a comparison of the mating behaviour of two subspecies. - Biol. J. Linn. Soc. 53, p. $153-163$.

Leighton, R. (1969). A note on the courting pattern of Pisaura mirabilis (Clerck). - Bull. Br. arachnol. Soc. 1, p. 25.

Le Pape, G. (1974). Relations entre comportement alimentaire et comportement sexuel chez Pisaura mirabilis (Araneida, Pisauridae). - Rev. Comp. Animal., p. 71-75.

Nitzsche, R.O.M. (1987). Brautgeschenk und Reproduktion bei Pisaura mirabilis, einschließlich vergleichender Untersuchungen an Dolomedes fimbriatus und Thaumasia uncata (Araneida: Pisauridae). - Dissertation, Universität Kaiserslautern, 339 pp.

- - (1988). Brautgeschenk und Umspinnen der Beute bei Pisaura mirabilis, Dolomedes fimbriatus und Thaumasia uncata (Arachnida, Araneida, Pisauridae). - Verh. naturwiss. Ver. Hamburg 30, p. 353-393.

Pénicaud, P. (1979). Dynamique d'une population de l'araigneé Pisaura mirabilis Cl. dans une lande bretonne. - Thèse Doctorat d'État, Université Pierre et Marie Curie, Paris, $89 \mathrm{pp}$.

Reinhold, K. \& Heller, K.-G. (1993). The ultimate function of nuptial feeding in the bushcricket Poecilimon veluchianus (Orthoptera: Tettigoniidae: Phaneropterinae). Behav. Ecol. Sociobiol. 32, p. 55-60.

Richter, C.J. (1970). Relation between habitat structure and development of the Glandulae ampullaceae in eight wolf spider species (Pardosa, Araneae, Lycosidae). - Oecologia 5, p. 185-199.

Sakaluk, S.K. (1985). Spermatophore size and its role in the reproductive behaviour of the cricket Gryllodes supplicans (Orthoptera: Gryllidae). - Can. J. Zool. 63, p. 16521656.

- (1986). Sperm competition and the evolution of nuptial feeding behaviour in the cricket, Gryllodes supplicans (Walker). - Evolution 40, p. 584-593.

Simmons, L.W. (1988). The contribution of multiple mating and spermatophore consumption to the lifetime reproductive success of female field crickets (Gryllus bimaculatus). - Ecol. Entomol. 13, p. 57-69.

— — \& Parker, G. (1989). Nuptial feeding in insects: mating effort versus paternal investment. - Ethology 81, p. 332-343.

Svensson, B.G., Petersson, E. \& Frisk, M. (1990). Nuptial gift size prolongs copulation duration in the dance fly Empis borealis. - Ecol. Entomol. 15, p. 225-229.

Thomhill, R. (1976). Sexual selection and nuptial feeding behavior in Bittacus apicalis (Insecta: Mecoptera). — Amer. Nat. 110, p. 529-548.

- - \& Alcock, J. (1983). The evolution of insect mating systems. — Harvard University Press, Cambridge.

Wedell, N. (1993). Mating effort or paternal investment? Incorporation rate and cost of male donations in the wartbiter. - Behav. Ecol. Sociobiol. 32, p. 239-246. 
- — \& Arak, A. (1989). The wartbiter spermatophore and its effect on female reproductive output (Orthoptera: Tettigoniidae, Decticus verrucivorus). - Behav. Ecol. Sociobiol. 24, p. 117-125.

Wickler, W. (1985). Stepfathers in insects and their pseudo-parental investment. Z. Tierpsychol. 69, p. 72-78.

- - (1994). On nuptial gifts and paternity. - Ethology 98, p. 165-170.

Zeh, D.W. \& Smith, R.L. (1985). Paternal investment by terrestrial arthropods. - Amer. Zool. 25, p. 785-805. 